\title{
ReVista ADM
}

EDITORIAL / EDITORIAL

doi: $10.35366 / 93096$

https://dx.doi.org/10.35366/93096

\section{El coronavirus se ha hecho viral.}

\author{
Coronavirus has gone viral.
}

\begin{abstract}
La cavidad oral es un reservorio de miles de especies microbianas, no sólo bacterias, también hongos, arqueas, incluso virus. Y no hay duda de que en el 2020 el coronavirus se ha vuelto viral...
\end{abstract}

Agustín Zerón*

E stamos viviendo y sobreviviendo a una época de grandes cambios; vivir es simplemente mantener una rutina que nos permita existir, y sobrevivir es enfrentarnos a una serie de dificultades o crisis que al vencerlas nos permite tener una mejor visión para la nueva etapa en nuestras vidas. De manera secular, los grandes cambios en la humanidad suceden en las primeras décadas de cada siglo. Los primeros años de cada 100 años, se han marcado por importantes sucesos históricos y ahora, en el siglo XXI, no sólo han sido los avances científicos, tecnológicos y culturales los que han enmarcado los grandes acontecimientos que, virtualmente, ya han cambiado nuestras capacidades o costumbres. $Y$ a pesar de tener una amplia red de información, con inteligencia artificial y con los grandes avances en la biotecnología, el mundo ha sido alcanzado por una nueva pandemia. Desde las siete plagas de Egipto hasta las más recientes de los últimos años, los microorganismos, los virus y sus diversos vectores han sido responsables de enfermedades y muertes.

Para nadie es desconocido el efecto biológico y el impacto económico que un nuevo virus nos ha traído, el «novel coronavirus». El coronavirus de 2019 es un betacoronavirus de RNA de cadena positiva que se ha denominado SARS-CoV-2 (Severe acute respiratory syndrome CoronaVirus-2) y que le ha dado el nombre a la pandemia del COVID-19 (CoronaVirus Disease-2019), el cual nos tiene a millones de seres humanos confinados

* Especialista en Endoperiodontología. Editor en Jefe de la Revista ADM. en nuestros hogares. $Y$ mientras unos cuantos pueden trabajar activamente haciendo home office, millones de personas tienen que seguir buscando el sustento familiar a pesar de nunca haber conocido al temible coronavirus.

El novel coronavirus sigue ganando la batalla al experimentado ser humano, hoy ya son cerca de dos millones de personas con diagnóstico de COVID-19, mientras que en estos días Estados Unidos ya es el país con más casos positivos al SARS-CoV-2, pero las cifras no se detienen y, lamentablemente, siguen aumentando las muertes. Hoy en el mundo ya habían fallecido más de 183,000 personas, estamos en el umbral de la pandemia.

La infección por coronavirus humano $(\mathrm{HCoV})$ causa enfermedades respiratorias con resultados leves a graves. En la actualidad, se conocen siete tipos de coronavirus que infectan a los seres humanos, y al menos seis de estos virus conviven con la humanidad desde el siglo XIX. En los últimos 15 años, hemos sido testigos de la aparición de varios HCoV zoonóticos y altamente patógenos: el coronavirus del síndrome respiratorio agudo severo (SARS-CoV) y el coronavirus HCoV-OC43 del síndrome respiratorio del Medio Oriente (MERS-CoV), y otros coronavirus con receptores celulares similares como HCoV-NL63, HCoV-229E, que producen también síndromes respiratorios leves o una gripe estacional, y el HCoV-HKU1 responsable de una neumonía bilateral, todos con variables en sus relaciones filogenéticas, y sólo estamos hablando de coronavirus.

La replicación del coronavirus está regulada por una diversidad de factores del huésped que induce drásticas alteraciones en la estructura celular y en la fisiología. La activación crítica de vías de señalización durante la infección por $\mathrm{HCoV}$ modula la inducción de la respuesta inmune antiviral con una intensa tormenta de citocinas proinflamatorias (interleucinas y quimiocinas, principalmente) que contribuyen a la patogénesis por el SARS-CoV-2. Estudios recientes han comenzado a revelar algunos aspectos fundamentales de la intrincada interacción HCoV-huésped 
en detalles mecanicistas. El conocimiento actual de los factores del huésped cooptados y las vías de señalización activadas durante la infección por $\mathrm{HCoV}$, tienen énfasis en la respuesta al estrés inducida por la infección viral, la autofagia, la apoptosis y la inmunidad innata. Existen varios biomarcadores relacionados, y principalmente dos (proteína C y ferritina) se están usando para predecir qué pacientes tendrán complicaciones graves, pues estas proteínas se encuentran mucho más altas en quienes tienen un peor pronóstico. Muchas de las muertes por COVID-19 se deben a una «tormenta de citocinas», una sobrecarga de proteínas inflamatorias que acaban colapsando al sistema inmune. En los escasos meses de investigación, la patogenia del SARS-CoV-2 y el fenotipo inmunológico de COVID-19 están todavía inconclusas, pero el fenotipo clínico de las trombosis es el de mayor interés.

Las comorbilidades como las enfermedades cardiovasculares, pulmonares, diabetes y síndrome metabólico (todas éstas relacionadas bidireccionalmente con las enfermedades periodontales), exponen significativamente mayor gravedad y letalidad a quienes desarrollan COVID-19. La genómica funcional ayuda a la comprensión más profunda de las enfermedades infecciosas al abarcar tanto al patógeno como a la respuesta del huésped. La comunicación entre las diversas enfermedades crónicas deja clara una interacción de productos de inflamación sistémica compartida por factores de riesgo genómicos y epigenómicos. Por ejemplo, la hiperlipidemia es una coincidencia genotípica en los pacientes que tienen diabetes, obesidad y periodontitis severa. Vale recordar que en el concepto de Salud Global, la salud oral es la piedra angular de la salud sistémica. Existen también datos que señalan a biomarcadores que son coincidentes entre los estados de comorbilidad de enfermedades crónicas.

Todo lo bueno y lo malo entran por la boca. Sabemos que en la infección por coronavirus no existen signos o síntomas reconocidos en la cavidad oral, pero es relevante conocer que el SARS-CoV-2 penetra a las células humanas empleando un receptor de la enzima convertidora ACE2 (Angiotensin-converting enzyme II). La enzima ACE2 puede expresarse en la cavidad oral por la presencia de múltiples receptores, en especial en la lengua y mucosa oral, por lo que la susceptibilidad infecciosa es mayor cuando el coronavirus entra por la boca y en las manos del mismo paciente. Los receptores ACE2 también se han observado en los linfocitos o macrófagos de las mucosas orales y de todo el sistema digestivo, y no solamente en los pulmones o sistema nervioso central, entre otros.
El coronavirus no está suspendido en el aire, el virus es oral y respiratorio, y las gotitas de Flügge pueden caer o llegar a nuestras manos y pasar a los ojos, nariz y boca. Los estudios realizados a la fecha señalan que el coronavirus de COVID-19 se transmite principalmente por contacto con microgotas respiratorias o gotitas de Flügge, más que por el aire. Karl Georg Friedrich Wilhelm Flügge, en la década de 1890, demostró que las gotitas que se expulsan de forma inadvertida por la boca y nariz al realizar acciones como toser o estornudar, incluso al hablar en voz baja, o simplemente al espirar, pueden transportar diversos microbios patógenos, tales como bacterias y virus. La mayoría de las microgotas provienen de la saliva, y pueden caer sobre objetos o superficies que rodean a la persona, y de esta forma, los demás pueden contaminarse si tocan estos objetos o superficies $y$, a su vez, con las manos contaminadas al tocarse los ojos, la nariz o la boca podrán darle entrada al virus a todo el sistema orgánico. Las aportaciones de Karl Flügge llevaron a la introducción de los cubrebocas para que en el siglo XIX los médicos los usaran durante las cirugías. Hoy en día, los respiradores N95 y los cubrebocas quirúrgicos (mascarillas, caretas y goggles) son ejemplos de los equipos de protección que utilizamos rutinariamente para la protección de partículas en el aire y de líquidos o aerosoles que pueden contaminar la cara.

El coronavirus está en la saliva y los odontólogos debemos tener un papel muy importante en la contención de la pandemia. Desde hace varios años sabemos que el biofilm oral también contiene diversos virus, y está demostrado su papel patogénico e interactivo con ciertas bacterias responsables de las lesiones severas de una periodontitis. El biofilm viral, al igual que el biofilm bacteriano, representan comunidades virales con mayor capacidad infecciosa y mejor propagación, comparado con las partículas virales libres, y podrían constituir un reservorio clave en infecciones crónicas. La etiopatogenia de una periodontitis grave incluye una coinfección por la asociación entre un complejo biofilm de virus y bacterias. El biofilm microbiano entre más organizado esté, será más difícil de combatir.

\section{¿TENDREMOS PRONTO UNA PRUEBA SALIVAL PARA EL CORONAVIRUS?}

Existen grandes ventajas en el uso de la saliva como método diagnóstico para diversas enfermedades, por la facilidad en la toma de la muestra y la menor exposición del personal en el procedimiento de toma de la misma, el consultorio odontológico es un lugar ideal para realizar 
las pruebas cuando el mismo paciente escupa en un recolector destinado al test biológico. Existen otras tres vías para explicar la presencia del virus en saliva: intercambio de gotas líquidas desde el tracto respiratorio a la cavidad oral; SARS-CoV-2 al estar presente en la sangre puede acceder a la cavidad oral a través del fluido crevicular; y por infección de las glándulas salivales, liberando el virus a la saliva a través del epitelio de los ductos.

El diagnóstico de COVID-19 se puede realizar teóricamente utilizando plataformas de diagnóstico salival. Se han detectado algunas cepas de virus en la saliva hasta 29 días después de la infección, lo que indica que una plataforma no invasiva puede diferenciar rápidamente los biomarcadores en saliva para mejorar la detección oportuna de la enfermedad. La saliva puede tener un papel fundamental en la transmisión de persona a persona, y el diagnóstico en la saliva puede proporcionar una plataforma de punto de prevención y contención de la infección por el coronavirus. El médico estomatólogo en su propio consultorio también podría tomar pruebas serológicas usando plaquitas de inmunoensayo de flujo lateral al detectar rápidamente anticuerpos (IgM-lgG). Todas estas pruebas continúan perfeccionándose.

Hace unos días los investigadores de la Universidad Rutgers recibieron luz verde de parte del Gobierno de EE.UU. para los primeros test de saliva que ayuden a diagnosticar COVID-19. Se necesitan todavía más estudios para investigar el potencial diagnóstico de COVID-19 en la saliva y su impacto en la contención del SARS-CoV-2. Las pruebas de diagnóstico son estratégicas para mitigar el riesgo de propagación, y como especialistas en el área de la medicina estomatológica jugamos un papel fundamental para controlar la pandemia de COVID-19. Muchos pacientes visitan al odontólogo con más frecuencia que los consultorios médicos, por lo que las prácticas en el consultorio odontológico deben unirse a la primera línea sanitaria contra COVID-19, ofreciendo formas de eliminar la posible transmisión y detectar portadores virales.

Recientemente, en la Guía para el Diagnóstico y el Tratamiento de COVID-19 (5. a edición) publicada por la Comisión Nacional de Salud de la República Popular de China, dicen que la clorhexidina, que usamos comúnmente como colutorio, podría ser menos efectiva para matar al coronavirus, aunque sabemos que sí inactiva otros virus. Dado que el SARS-CoV-2 es vulnerable a la oxidación, se recomienda un enjuague bucal preprocedimiento que contenga agentes oxidantes (peróxido de hidrógeno al $1 \%$ o yodopovidona al $0.2 \%$ durante un minuto), con el fin de reducir la carga salival de los microbios orales, incluido el coronavirus.

Necesitamos tomar muy en serio, y con mucha precaución, el papel que tenemos para ayudar a minimizar la propagación y el riesgo de infección en nuestra comunidad. En algunos estudios se ha podido evaluar que cuando una persona entra en contacto con otra persona COVID positivo, su saliva contiene grandes cantidades de coronavirus, volviéndose altamente contagioso, aun estando asintomáticos durante días pueden ser el vector de transmisión familiar y en su grupo social cercano. Toda la comunidad odontológica debemos reforzar las rutinas, no sólo de bioseguridad y control de infección, sino también en la instrucción de higiene oral

Figura 1:

El coronavirus SARS-CoV-2 es el responsable de la pandemia de COVID-19.

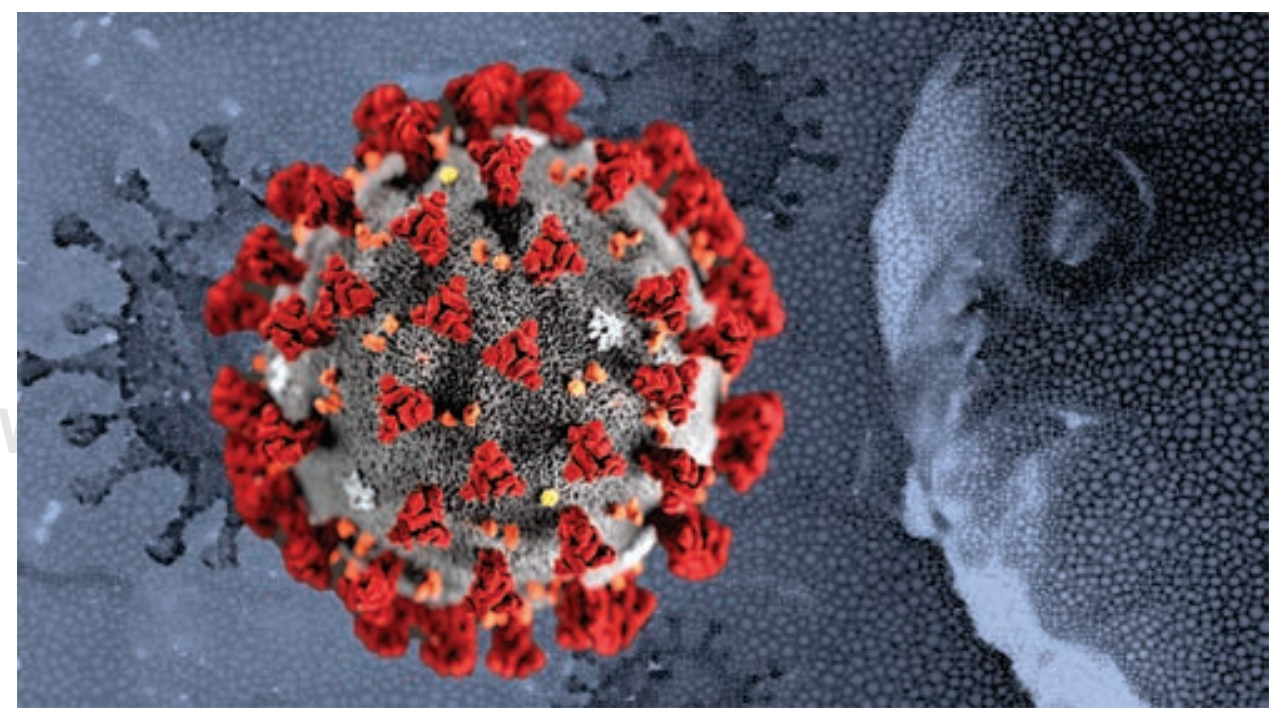


para disminuir los riesgos de proliferación viral y daño sistémico, particularmente con los pacientes que están medicamente comprometidos. Desinfectar el cepillo de dientes es fundamental.

Los profesionales de la salud oral, con la experiencia de varias décadas, hemos aprendido a enfrentarnos a diversas cargas epidémicas, y por esta capacidad jugamos un importante papel en la prevención de la transmisión de coronavirus y la contención de COVID-19. En esta crisis sanitaria resulta importante actualizar las medidas de control de infecciones durante la práctica odontológica, para bloquear las rutas de transmisión de persona a persona en consultorios, clínicas y hospitales. Y así como realizamos mediciones de glucosa, hemoglobina glucosilada, medición de la tensión arterial, etcétera, es preponderante realizar también en el consultorio pruebas rápidas de COVID-19. Las pruebas de diagnóstico ayudarán a mejorar las estrategias efectivas de prevención, contención y mitigación, y no solamente cuidar la propagación a través de los aerosoles.

Para terminar, una luz se avizora al final de este túnel de confinamiento; hace poco se dio a conocer una buena noticia, y es que en Estados Unidos anunciaron que científicos probaron con éxito una vacuna prototipo en ratones, capaz de neutralizar al coronavirus, y en unos meses será probada en humanos. Dicha fórmula se llama PittCoVacc, esta vacuna en parche produce anticuerpos específicos para el SARS-CoV-2 y sería, hasta el momento, una esperanza de cara al futuro de la medicina genómica y prevención personalizada.

\section{ESTRATEGIAS DE PREVENCIÓN, CONTROL, CONTENCIÓN Y MITIGACIÓN DEL COVID-19 EN EL 2020}

- Factores culturales y conductuales: influyen en las posibilidades de contención, hábitos higiénicos y alimentación saludable.

- Factor de experiencia: ayuda a prevenir y contener cuando los primeros brotes son detectados.

- Factor de evidencia: es el desarrollo biotecnológico para diagnóstico temprano.

- Factores tecnológicos: smart health communities, Internet de las cosas (IoT), Big Data (ALIPAY, códigos QR de movilidad y geolocalización de enfermos).

En este número incluimos tres interesantes artículos relacionados al coronavirus; también temas como el sarcoma de Kaposi asociado con VIH-SIDA, apoptosis en liquen plano, seguridad del paciente de acuerdo con la CONAMED y evaluación de higiene oral en pacientes con obesidad. Además, información actual sobre los riesgos y complicaciones asociados con injertos de origen bovino, donde se discuten las contradicciones y sesgos de las publicaciones en el llamado «fenómeno de Proteus», preparado especialmente por el Prof. Hessam Nowzari.

Correspondencia:

Agustín Zerón

E-mail: periodontologia@hotmail.com 